\title{
Students' L2 Refusal Appropriateness and Accuracy
}

\author{
I Made Rai Jaya Widanta \\ Mechanical Engineering Department, Bali State Polytechnic, Bali, Indonesia \\ Ni Putu Somawati \\ Tourism Department, Bali State Polytechnic, Bali, Indonesia \\ I Wayan Dana Ardika \\ Civil Engineering Department, Bali State Polytechnic, Bali, Indonesia
}

\begin{abstract}
The study aimed at investigating refusal strategies performed by foreign learners of Indonesian language. Specifically, it was focused on researching strategies of refusal used by the participant, emerging frequency of each strategies, as well as appropriateness and accuracy of each strategy used. Sixty students majoring in Tourism were involved in the project. Discourse completion task (DCT) containing an invitation using three sociocultural aspects of low power (-P), low distance (-D), and low rank of imposition (-R) was used to elicit participants' refusal strategies. Taxonomy of refusal proposed by Beebe, Takahashi, and Uliss-Weltz (1990) was applied to recognize refusal strategies used by participants. Result of the study revealed that there were three strategies of 'direct, indirect, and adjunct to refusal' used by participants in responding the invitation. However, two new sub-strategies found to enrich indirect strategies, they are 'alternative (change subject)' and 'telling wish'. Dealing with participants' appropriateness and accuracy, it could be concluded that their appropriateness in producing semantic formulas were higher than their accuracy $(96,55 \%$ and $\mathbf{4 0 , 8 3 \%}$ ) respectively. In addition, there were two contradictive propositions finally underscored upon analysis of appropriateness and accuracy. In term of appropriateness, it is implied that L2 proficiency does not guarantee learners' high appropriateness, which is in contrast with the Cordina-Espurz's (2013) finding. However, in term of accuracy, it implied that the lower learners' L2 proficiency is the lower accuracy level they are in, which is in line with Cordina-Espurz's (2013) finding.
\end{abstract}

Index Term - proficiency, refusal strategies, appropriateness, accuracy

\section{INTRODUCTION}

Refusal is considered to be one of very challenging speech acts (SA) as it can threaten interlocutor's face, thus it requires high level of speakers' pragmatic competence (Ellis, 2008). According to Tian (2014), the success of a speaker in performing appropriate SA of refusal depends very much on his or her level of linguistic proficiency. The higher one's proficiency level of linguistic is, the more appropriate utterances of refusal he or she can perform. In order be proficient he or she should learn pragmatics. One of effective method for learning pragmatic is explicit and implicit learning (Widanta, 2017), i.e. the acquisition of pragmatics which is done by a real learning (with an instructor in class) or by non-class activity. The forms and function of pragmatic resources (pragmalinguistics) as well as the forms with their proper context (sociopragmatics) can be introduced explicitly to learners in order for them to be able to enhance their pragmatic awareness, and practice using and producing appropriate utterances sociocultural. In spite of pragmatic intervention, speakers' exposure to pragmatics by doing social interaction with speakers of the target language (implicitly) was also proved to be helpful (Widanta, 2018) to improve one's pragmatic competence.

There are a number of studies undertaken in refusal. Some refusal studies focused on investigating effect of L2 to L1 pragmatic (Aver \& Brumberek-Dyzman, 2008), effectiveness of DCT and oral role play to trigger speakers' production of refusal (Martinez-Flor, 2013), speakers' politeness strategy (Felix-Brasdefer, 2004), cross-culture refusal (Lin, 2004), effect of proficiency to speakers' production (Cordina-Espurz, 2013), learners' pragmatic strategies (Tian, 2014), nonnative speakers' production of speech acts of refusal (Satar, Lah, Sulaeman, 2011), effect of study abroad to learners' proficiency (Ren, 2012), and pragmatic transfer (Abed (2011).

Avet \& Brumberek-Dyzman (2008) focused their study on effect of using L2 to L1 speaker. The research involved one hundred and six Polish students who learned English as a second language (L2). The participants were divided into two groups, 22 Polish students who learned English as L2 were grouped in group one and eighty four university students of Biology were grouped in group two. The study was aimed at investigating whether knowing and using other language will affect students' pragmalinguistic of first language (L1). In addition, the study was also in purpose to know similarities and differences of frequencies of use of semantic formulae of refusals of the two groups. By applying discourse completion task (DCT) containing situations on the basis of Brown \& Levinson (1987), they were to complete 
spaces provided in DCT. Result of analysis revealed that there was not a significant difference on pragmatic competence of both groups. It can be concluded that knowing and using L2 do not influence learners' L1 pragmalingusitic competence.

Martinez-Flor's (2013) work on refusal, on the other hand, was aimed to investigate variety of number and kinds of refusal. The main purpose of the research was to see effectiveness of two instruments (DCT and oral role play) to trigger participants to produce SA. Sixteen pairs of English majored students of advanced were given two instruments, written DCT and oral role play. Two hundred and eighty eight response samples obtained were compared to see effectiveness of both instruments. Result of analysis indicated that both instruments were effective.

Felix-Brasdefer (2004) investigated refusal SA to see politeness strategies used by Spanish native speakers (NS) and non-native speakers (NNS) when performing refusal SA. In addition, the study was also aimed to see if length of stay abroad affected their production of refusal strategies. To elicit data of refusal SA, the study applied oral role play and verbal report (compared to Avert and Brumberek-Dyzman, 2008 and Martinez-Flor, 2013). Both instruments were utilized as they are easy to obtain complete verbal interaction. In addition, they ease researcher to control conversation and to reflect awareness on the use of refusal. By applying both instruments and involving sixty four participants (40 NS students and twenty four NNS students) it was obtained that there are three hundred and four refusal interactions done by research participants. The sequence of SA was made, starting from head act, pre and post refusal and across conversational turn. The result showed that participants were able to negotiate using lexical mitigation, syntagmatic, and higher solidarity and almost similar indirectness, which is almost similar to production of NS. It can be summarized that both speakers having experience to live in a native speakers' country and to live at home could show the same level of competence. Clearly, experience to study abroad is not visible to improve learners' pragmatic competence.

Study on refusal by utilizing written instrument was undertaken by Lin (2014). The study involved ninety participants, they are Mandarin language native speakers, Chinese EFL learners, English native speaker of American. The study was in purpose to see what cross culture refusal (Chinese and English) are they and how Chinese EFL learners of Chinese make refusal SA. The data raising instrument was DCT written in English and Chinese using three refusal situations in order to know participants' sociopragmatic participants. The participants were asked to read instruction and examples and complete the instruments for thirty minutes before the data was coded on the basis of Bebee's (1990) scheme. The data was analysed by using statistics. The result of analysis revealed that there was different strategies of refusal between three groups. Chinese EFL learners tended to make face threatening SA a lot higher than NS of China and English NS of America. I addition, there was similarity in refusal perception about face threatening acts of Chinese NS and English NS of American in terms of the way how they use 'indirectness' and 'adjunct'.

Research in L2 using written instrument was also undertaken by Cordina-Espurz (2013). Using one hundred and ninety two participants of master program students majoring in education and English language philology divided by four groups (beginner, elementary, lower intermediate, and upper intermediate), there were two purposes based on which it was carried out. First, to recognize whether or not high proficiency learners were able to produce more refusal strategies than students having lower competencies. Second, to see whether or not learners with high proficiencies were able to produce more refusal strategies than learners with lower competence level. Data were pursued by using DCT with some contexts, such as bank, university, bread fabric, book store, with some request situations with controlling variable, such as social status, social distance, and gender. Participants' responses were analysed using refusal taxonomy, number of strategy used, and their appropriateness. The data obtained were analysed using ANOVA to see difference significance among the groups. Result of analysis found that the most commonly used refusal strategies were used by 'beginner' followed by 'lower intermediate, elementary and upper intermediate'. Beginner level made the most direct strategy than other groups. However, 'adjunct' were mostly made by upper intermediate group. It implied that the lower proficient learners performed lower competence.

Tian (2014) studied refusal of Chinese EFL learners by applying oral role play with six scenarios. The scenarios were constructed on the basis of social variables of PDR (Brown and Levinson, 1987). The study was aimed at investigating learners pragmatic strategies applied in performing SA of refusal in English and factors influencing their choices of strategies as well as examining their pragmatic competences L2. In addition, it was also undertaken to find out pedagogical implication it could propose. Participants were given six situations before role play was administered. Participants' utterances of refusal SA were recorded. Its transcripts were analysed by using politeness theory (Brown and Levinson, 1987). Result of analysis showed that participants were motivated to use 'indirect strategies' in six situations. They used non performative expressions in the 'direct refusal', e.g. Don't pay, I can't leave my family now, No, I don't want". They also used reasons to complete their refusals, such as "It's very cheap, I have a little child, I already borrow it to Li Mei. My tape recorder is broken". The result could prove that aspects of linguistics, pragmatics and sociocultural were factors which influence their strategy choices.

Sattar, Lah, dan Sulaeman (2011) also investigated refusals in English to see semantic formula mastered by Malay students in refusing a request in academic context. The study involved sixty students of undergraduate and post graduate program. The study used DCT with some situations. DCT was designed on the basis of two variables, i.e. 'relative power' and 'social distance'. They were given written situation in English and were requested to write what they would express for each situation. Data of DCT were then examined and categorized based on Bebee's taxonomy 
(1990), particularly 'direct refusal, indirect refusal, and 'adjunct to refusal'. The data were analysed using semantic formula, such as 'a reason, an explanation, and 'an alternative' (Fraser, 1981; Olshtain and Cohen, 1983; Bebee, et.al. 1990). Analysis result obviously showed that Malay students prefer using 'indirect refusals', 'apology' and 'explaining'. That semantic formula was mostly used as the result of participants' culture influence. In direct strategy, they avoided using 'no', that they used negative ability instead. On direct strategy, they tended to use 'excuse' and 'explanation, and 'regret' followed by alternatives, wish, self-defence, and philosophy.

Ren (2012) also investigated development of learners' pragmatic particularly, SA of refusals. It was focused on investigating influence of learning environment to L2 pragmatic development of two groups of participants, group of participant with experience of study abroad and group of participants with experience of study in Indonesia. The study was also aimed at investigating to what extent study abroad influences their choice of pragmatic, their vocabulary and adjunct of refusals, and to what extent study abroad influence their refusal strategies. Research participants involved were twenty groups with study abroad experience and twenty groups of participant with study at home. The instrument used to pursue data was multimedia elicitation task (MET), i.e. computer multimedia-based DCT with eight scenarios. In its implementation, participants were given time to watch one slide in computer and listen to direction and start the utterance recorded and respond them orally. MET was given three times (pre-test, middle test and post-test). Data of test result with MET were grouped into three groups, 'direct refusal', 'indirect refusal' and 'adjunct to refusal'. Result of analysis revealed that study abroad group tended to do 'opt out' strategy consistently for the three tests, had pragmalinguistic vocabulary with significant development, doing opt out strategy as their new strategy. The 'at home' group also made opt out as a new strategy. They often used opt out to respond to friends' suggestions. Overall, study abroad influenced their sociopragmatic choice of SA.

Research on refusals was also carried out in term of language transfer (Abed (2011). Using instrument of written DCT, the research involved fifty five participants. The research was aimed at uncovering pragmatic transfer process on EFL learners of Iraq on refusal, their pragmatic awareness, differences between Iraqi speakers and American speakers in using refusal strategies and adjunct, as well as differences between female and male Iraqis speakers in using the strategy. The participants were given DCT via email. Data of semantic formula were classified based on Bebee et.al. (1990). Basically, the three groups of participant used indirect strategy more frequently than direct strategy. Iraqis more frequently used 'statement of excuse, reason, explanation, statement of regret, statement of wish', 'refusal adjunct'. American speakers tended to use 'statement of philosophy, statement of acceptance' as refusal and 'evidence' particularly 'silence'. Iraqi speakers are considered to be aware of pragmatic. They tended to adopt their L1 when they refused.

Studies on refusals SA varied in terms of instruments used, participants involved, as well as data analysing method applied. Of the studies related to refusals, some studies applied DCT as data collecting instrument (Avert, Brumberek, Dyzman (2008), Sattar, Lah, Sulaeman (2011), Abed (2011), Ren (2012), Cordina-Espuzs (2013), dan Lin (2014). This study also used DCT as the min instrument of data colleting. Some studies combined two instruments of DCT with multimedia elicitation task (MET) (Ren, 2012), or modified DCT with other situations, such as scale response questionnaire (Lin, 2014). Almost all studies used data analysing instrument of statistical tools. Tian's (2014) works used pure oral role play, Felix-Brasdefer's (2014) study combined oral role play with verbal report, and Martinez-Flor (2013) combined oral role play with DCT. Tian (2014) designed oral role play using politeness theory proposed by Brown and Levinson (1987), and the use of standard taxonomy or semantic formula (Beebe, 1990; Olshtain and Cohen, 1983) to analyse participants' production of refusal (Sattar, Lah, and Sulaeman, 2011; Lin, 2014, Abed, 2011).

Taguchi (2006) investigated students' ability to produce a speech act of request. Fifty-nine Japanese students of English were given oral role play to make request. The participants were divided into two proficiency levels based on their TOEFL scores, 29 students are for higher proficiency and 30 students are for lower proficiency level. The request realization performed by the participants were analysed quantitatively by rating performance on a six-point scale to recognize their appropriateness $(5=$ excellent, $4=$ good, $3=$ fair, $2=$ poor, $1=$ very poor, and $0=$ no performance $)$. Qualitative method was applied to measure their level of directness of every utterance. Oral role play card was developed to elicit students request production. To cards were made into two types by implementing three aspect, interlocutor power (P), distance (D), and rank of imposition (R), they are PDR-low and PDR high. Blum-Kulka's CCSARP framework (1998) was used to code students' performance before being analysed. The result revealed that L2 proficiency influence over all appropriateness. The presents study was done pursuant to three basic research questions, they are as follows.

1. What refusal strategies were used?

2. How frequently was each strategy used?

3. How appropriate and accurate were those strategies?

\section{METHOD}

The research participants were sixty students of semester three majoring in tourism, particularly in tour and travel study program. The involved participants consist of forty male and twenty female who were from two classes, class A and class B. Their ages ranged from nineteen until twenty years old. Based on curriculum implemented in this class, they had studied English for three semester, both general English and English for specific purposes (English for tour 
and travel), but not English pragmatics. Special English proficiency test to recognize in what level of proficiency they have was not administered, however on the basis of their English lecturer's observation, they were in elementary and pre-intermediate level.

DCT was applied to elicit participants' refusals competence. DCT was designed with only one situation. It was designed by including only one aspect of sociology, i.e. minus power $(-\mathrm{P})$ and minus distance $(-\mathrm{D})$. The purpose of the card was to recognise students' pragmatic competence particularly in refusal strategies using only one aspect of sociology, as the class has not been introduced with pragmatic matter in prior. This is a pilot project which can lead to a more complex research in the future. As they have not known pragmatic, only a simple case or situation using common level of English (English used commonly with friends which does not requires formal and polite form of sentences) was used. The situation requires that students have to refuse their friends' invitation for a movie as they have to finish a house assignment. The situation was printed in a piece of paper which provides spaces beneath for participants to write their refusals to the invitation.

Prior to the test to elicit participants' refusal strategies, they were informed about what the test was used for. They were simply informed that the activity was not having special purpose (e.g. having relation with their academic achievement in class). It was done to avoid their feeling worried or reluctance to answer the DCT. For its implementation, they were introduced with the instrument first. Furthermore, they were introduced with the purpose of the activity they will participated in. Mechanism of how to answer the DCT was also delivered to participants. They were showed the DCT sheet on which they had to write their response. To do so, it took about five until seven minutes to display them the sheet and how to feel it. Regulation was also explained to them that they were not allowed to open books or any other devices which can help they ease to their work. I addition, they were informed that this test took one of their in class meeting without providing its replacement upon the test.

The instrument to elicit their refusal SA performance was distributed at the end of the semester. This moment was taken without any special intention. It was decided since it was impossible to interrupt students' learning activity before the semester ended. However, they students were not introduced or taught with materials and knowledge about pragmatic and its related materials. They took Intermediate English which was focused on general English. As the regular subject pursuant to curriculum, they had to study for a semester and take final test at the end of semester. The elicitation activity was undertaken on a meeting prior to the final test. Each class took twenty five until thirty minutes to do the test. Each student in class A was distributed the DCT and was given chance to complete the DCT directly without any permission to open the book or to use Google translate device. Upon thirty minutes, their work were collected and the test was continued for class B. Students work was then collected and explicated. Students' refusal strategies used ware listed and grouped and compared to refusal taxonomy proposed by Beebe, Takahashi, and UlissWeltz (1990) to see differences and similarities, frequency of each strategy emergence, and their refusal strategies' level of appropriateness and accuracy.

TABLE 1.

REFUSAL TAXONOMY (BEEBE, TAKAHASHI, AND ULISS-WELTZ: 1990)

\begin{tabular}{lll}
\hline No & Strategies & Realization \\
\hline 1 & Direct Strategies & No/ I refuse \\
& Bluntness & I can't, I don't think so \\
& Negation of Proposition & \\
\hline 2 & Indirect Strategies & It look like I won't be able to go \\
& Plain indirect & I can't, I have a doctor appointment \\
& Reason/ Explanation & I am so sorry, I can't \\
& Regret/ Apology & I would join you if you choose another restaurant \\
Alternative: & I can't go right now, but I could next week \\
- Change option & Under the current economic circumstances, you should not be asking for \\
- Change time & a rise right now \\
Disagreement/Discussion/Criticism & I can't. It goes against my beliefs \\
& Statement of principle or philosophy & Ignoring/silence \\
& Avoidance: & Hedging : Well, I'll see if I can \\
& - Non-verbal & \\
- Verbal & \\
- Change topic & \\
- Joking & \\
- Sarcasm & \\
\hline Adjunct to Refusal & \\
Positive opinion & That's a great idea, but... \\
Willingness & I'd love to go, but.... \\
Gratitude & Thanks so much, but... \\
Agreement & Fine, but.... \\
Solidarity/Empathy & I am sure you will understand \\
\hline
\end{tabular}

\section{RESUlT AND DISCUSSION}

\section{A. Refusal Strategies and Their Frequency of Emergence}


The following table introduces the global figure of refusal strategies used (pursuant to taxonomy proposed by Beebe, Takahashi, and Uliss-Weltz; 1990) and their emergence frequency.

TABLE 2.

EMERGING FREQUENCY OF EACH STRATEGY

\begin{tabular}{lll}
\hline No & Strategy Used & Frequency of Emergence \\
\hline 1 & Direct Strategies & $7,2 \%$ \\
2 & Indirect Strategies & $52,7 \%$ \\
3 & Adjunct to Refusals & $40,0 \%$ \\
\hline
\end{tabular}

Result of analysis showed that there were three types of strategies speakers used when refusing an invitation, i.e. 'direct strategy', 'indirect strategy' and 'adjunct to refusals'. However, some of realization patterns of each strategy were a bit different from those drawn by Beebe, Takahashi, and Uliss-Weltz: (1990). Each strategies was used differently in frequency depending on speakers L2 proficiency and knowledge of pragmatics.

It can be clearly seen that 'indirect strategy' was the most frequently used strategy, followed by 'adjunct to refusals', and 'direct strategy' was the least, i.e. 52,7\%, 40,0\%, and 7,2\% respectively. The presence of indirect strategies weighing out the rest strategies indicated that the participants were (if not very) competent pragmatically, as ability to perform indirect strategy requires speakers' better knowledge of pragmatic(both pragmalinguistics and sociopragamtics) rather than direct strategies. Ability to produce indirect refusals speech acts requires speakers' broader knowledge of politeness as well.

Although the emergence of 'adjunct to refusals' was less frequent than 'indirect strategies' (40\% under 52,7\%) the difference was not considered distinctive as adjunct to refusals are considered to be the most difficult of the three strategies. It requires that speakers are to be able to make rhetorical sentences. In addition to this, adjunct to refusals provides a lot more limited examples of realization patterns or semantic formulas which limits speakers' choice of sentences patterns to adopt. The table 2 beneath obviously shows how often each strategy was used by the speakers.

TABLE 3.

FREQUENCY AND SEMANTIC FORMULA OF DIRECT STRATEGY

\begin{tabular}{|c|c|c|}
\hline \multicolumn{3}{|c|}{ Direct Strategies } \\
\hline No & Semantic Formulas & Frequency of Emergence \\
\hline 1 & Bluntness & $75 \%$ \\
\hline 2 & Negation of Proposition & $25 \%$ \\
\hline
\end{tabular}

Direct strategy is the least strategy speakers used when producing refusals to an invitation. It only provides two semantic formulas, 'bluntness' and 'negation of proposition'. 'Bluntness' was delivered more frequently than 'negation of proposition'. It was used $75 \%$ between the two. 'Negation of proposition' was used only for $25 \%$ or one forth. This may be caused by the reason that 'bluntness' was in form of very short or simple utterance "no' or "I refuse" rather than the latter strategy using "I can't, I don't think so". However, the utterance 'no' was used limitedly. One reason may be in line with the fact is the speakers' L2 proficiency level. Since the speakers are mostly from pre intermediate level, they were able to avoid to direct even though they were able to do so. Telling 'negation of proposition' of "I can't" and "I don't think so" was considered impolite even though the interlocutor is a person who has similar or -P, -D, and - R. The avoidance of uttering both types of utterance indicates that the speakers had knowledge of sufficient L2 pragmatics. This if proved by the fact that only lass proficient participants produced these utterances. It indicated that the more sufficient the speakers are in L2, the less direct speech acts they produce. It is in line with the finding of Cordina-Espurz (2013).

Indirect strategies (Table 4) almost has similar feature with 'adjunct to refusal' strategy (Table 5), although indirect strategies were the most used strategy in the speakers' refusals production, in term of number of semantic formulas were used. There were ten semantic formulas of each used by speakers. However, their types and frequency of use were totally different. There were ten semantic formulas used to respond to the role play card of invitation. Of the ten semantic formulas, 'regret/apology' was the most formula in use $(82,7 \%)$. The frequency was very extremely higher than the others. It was caused by the fact that speakers mostly used the expression 'I'm sorry' to initiate their refusals expressions. This clause seemed to be very common for them. The clause, as icon of refusal, was placed in various locations, i.e. at the front of sentence, in the middle, or sometimes at the end. One sentence mostly contained one expression of 'I'm sorry". Some sentences even had two or more the expression containing 'sorry" even though it was used with less complete sentences. Some of them use e it in a correct pattern of sentence and some of them used it in non-correct sentence patterns, such as 'I'm sorry', 'Sorry', 'I'm sorry bro', 'I do apologize', and 'sorry I cannot'.

'Reason/Explanation with alternative (Change time)' was the second most frequently used refusal strategies. This type of utterance contains two main expressions, reason/explanation and alternative with expression of changing time. This expression occurred 13,7\%, the second after 'regret/apology'. Basically, it is a speech having similar expression of saying sorry, however, it is added with clause telling reason why the speakers refuse the invitation and giving an alternative particularly change of time. The specific feature of this expression is the expression of telling reason indicated with the word "because' and expression of giving alternative, e.g. "I sorry Arik, I can not join because I have to do an English assignment with Astina. I can go to Concert with you may be next time". Even though the sentences 
were made with incorrect grammatical aspects, such as the omission of verb 'am', the spelling of 'cannot', but this sentence is still accepted as it can successfully deliver meaning.

TABLE 4.

FREQUENCY AND SEMANTIC FORMULA OF INDIRECT STRATEGY

\begin{tabular}{|c|c|c|}
\hline \multicolumn{3}{|c|}{ Indirect Strategies } \\
\hline No & Semantic Formulas & Frequency \\
\hline 1 & Regret/Apology & $82,7 \%$ \\
\hline 2 & Reason/Explanation with Alternative (Change Time) & $13,7 \%$ \\
\hline 3 & Regret / Apology With Telling Possibility & $3,4 \%$ \\
\hline 4 & Regret/Apology with Willingness, Alternative (Change Time) & $10,3 \%$ \\
\hline 5 & Regret/Apology with Willingness & $6,89 \%$ \\
\hline 6 & Regret/Apology with Telling a Wish & $3,4 \%$ \\
\hline $7 *$ & Telling Wish & $3,4 \%$ \\
\hline $8^{*}$ & Regret/Apology, Willingness, Alternative Change of Subject & $3,4 \%$ \\
\hline 9 & Regret/Apology, Gratitude, Willingness & $3,4 \%$ \\
\hline 10 & Willingness & $3,4 \%$ \\
\hline
\end{tabular}

Two feasibly noted finding upon analysing data of indirect strategies was expression of 'telling wish' $\left(7^{*}\right)$ and 'alternative (change subject)' $\left(8^{*}\right)$. Although there were only two expressions containing 'telling wish' and was specially attached in an expression of telling regret or expressed individually, telling wish can be considered special. The expressions 'I wish I can watch Lolot band concert because it is my favourite band' and 'Hallo, I wish I can, but next Saturday night I am really busy...' were specially expressed with distinctive attempt. Thus, this strategy can be added exclusively (7*) as it cannot be included either strategy of indirect, direct or adjunct to refusal.

'Alternative (Change subject)' was also the possible nomenclature for the expression: '...I'd love to but I can't, I'm sorry, because on Saturday night I should to do my English homework, may be you can invite Fedira or Iren for accompany you come to the concert'. Even though the expressions contains some grammar mistakes, let's ignore it and focus our attention on the use of giving 'alternative (with Change of subject)' or person the speaker suggested the hearer to invite. This is excluded on taxonomy proposed by Beebe, Takahashi, and Uliss-Weltz (1990) which exposes only two kinds of giving alternative, i.e. 'change option' and 'change time'. However, it does not clearly advice where should the case of expression above be inserted.

In spite of similar number of semantic formulas, 'adjunct to refusal' (Table 5) differs from 'indirect strategies' in terms of kinds of semantic formulas they performed and frequency they were produced. On the basis of data, 'willingness' strategy was the most strategy used by the speakers. It was used $36.3 \%$ by the speakers. Willingness was quite simple to make. It is used to express speakers' desire to do a thing or an activity. In its implementation, this strategy was placed at the beginning of sentence, in the middle or at the end of the sentence. However, the data shows that it is mostly used at the beginning of sentence. It was made in a number of different forms, patterns, depending on the topic where or when it is used. Some of willingness ware initiated with greeting, such as 'Hey friend, actually I would like to join with you,..."Hai Adi, I'm fine thank you, oh I'd love to but...', “Oh men, I want to watch this but I can't because...", Hallo Riris, I'm very interested your invitation but I'm sorry...”, Hi, Andre, actually I want to go to the concert but...", 'Hallo, aright, I want to join with you for see the concert, but...', 'Hai, Recha, actually I want to see the concert with you but...", 'Hallo Jul, actually I want to see the concert with you but...', 'Wow, I really want to watch the concert but sorry...'. Some of expressions of willingness were delivered with polite choice of expression, like 'I would like to join with you...', Oh, I'd love to...', but most willingness was expressed with less honorific expressions, such as 'I want to watch this but...', I'm very interested your invitation...', I want to go to the concert...', I want to see the concert...', I really want to watch the concert..'.

Telling 'gratitude' and 'positive opinion' were similar in frequency of use. Both refusal strategies of adjunct were used $36.63 \%$. Both strategies were used either individually or attached with other expressions. Expression of gratitude also varied either in its pattern or in words choices. The expressions are 'I'm so happy you invite me for join concert', Thanks for the invitation', 'I would like to thank for invitation', 'Thank you very much for invited me', 'Your mother is very kind'. The embedded expression of gratitude were also produced by the speakers, such as 'Hi friend, I am so happy you invite me for join the concert, but I'm sorry I'm busy because I have an appointment with my friends', 'Thank you very much for invited me to go to the concert and I also think it would be amazing and awesome if we go together, but I'm sorry, I couldn't go because I have an English assignment and...', 'It was nice to hear you get a concert tickets from your old brother as a birthday gift and I'm so thank you to know you invited me, but I'm really-really sorry Delvi'. One expression to express gratitude even consisted of three different semantic formulas as the speaker had rich enough pragmatic treasure, by saying 'Hey friend, I'm so happy you invite me for join concert, but I'm sorry, I'm busy because I have an appointment with my friend. May be next time we have look at concert together'. This expression even consists of three formulas, such as 'gratitude', 'reason/explanation', and 'alternative: change time'.

Positive opinion was also delivered variously, either with single expression or embedded ones. The expression 'It's a great idea actually, but...', 'That sounds lives ouch fun..' were expressed with only a single clause. The embedded semantic formula used to express positive opinion were: 'Oh, this is good, I like that. But sorry, I can't go there on Saturday night because...', 'Hi Alfa, That sounds great but I am sorry, I must finish my English assignment with my 
team work at the same time..'. Positive opinion which consists of three semantic formulas was also found in the data: 'Hi, Alfa, that sounds great but I am so sorry, I must finish my English assignment with my team work at the same time. But I can't at the time, I'm so sorry Alfa, I hope we can do it some other time'.

The embedded expressions of telling 'gratitude' and 'positive opinion', although only one found' indicates that speakers competent enough to perform refusal strategies, although grammatically less accurate. They were able to made up their mind to try constructing longer sentences to promote indirectness.

The rest formulas, including 'willingness \& promise', Gratitude \& regret/apology', 'gratitude \& positive opinion', 'positive opinion \& reason/explanation' were delivered far less frequently, with more or less $4,5 \%$. Willingness \& promise was conveyed only one time. The expression says 'Hallo, alright, I want to join you for see the concert, but I have to do an English assignment with my friend at the same time on next Saturday night. I do apologize for this, the next time I will join to see the concert' was considered to be a remarkable elaboration as the speaker could produce a new supplement expression of 'promise'. Promise is not included in the refusal taxonomy proposed by Beebe, Takahashi, and Uliss-Weltz (1990). This semantic formula can be added to enrich the taxonomy that formula of giving promise: 'I will ...' can be used to refuse an invitation. However, 'giving promise' should be best inserted in the indirect strategies of refusal.

TABLE 5.

REQUENCY AND SEMANTIC FORMULA OF DIRECT STRATEGY

\begin{tabular}{lll}
\multicolumn{2}{c}{ REQUENCY AND SEMANTIC FORMULA OF DIRECT STRATEGY } \\
\hline \multicolumn{2}{l}{ Adjunct to Refusals } & \\
\hline No & Semantic Formulas & Frequency of Emergence \\
\hline 1 & Gratitude, Reason/Explanation, Alternative (Change time) & $36,3 \%$ \\
2 & Willingness & $13,63 \%$ \\
3 & Positive Opinion & $4,5 \%$ \\
4 & Positive Opinion, Reason/Explanation & $13,63 \%$ \\
6 & Gratitude & $4,5 \%$ \\
7 & Gratitude, Positive Opinion & $4,5 \%$ \\
8 & Gratitude, Regret/Apology & $4,5 \%$ \\
9 & Positive Opinion, Regret/Apology, Willingness & $4,5 \%$ \\
10 & Willingness, Promise & \\
\hline
\end{tabular}

The feasible findings upon analysis successfully added variation of refusal strategies proposed by Beebe, Takahashi, and Uliss-Weltz (1990). The two new finding of indirect strategies, i.e. 'telling wish' and 'alternative (change subject) are included in the following elaborated taxonomy.

TABLE 6.

ELABORATED REFUSAL TAXONOMY (BEEBE, TAKAHASHI, AND ULISS-WELTZ: 1990)

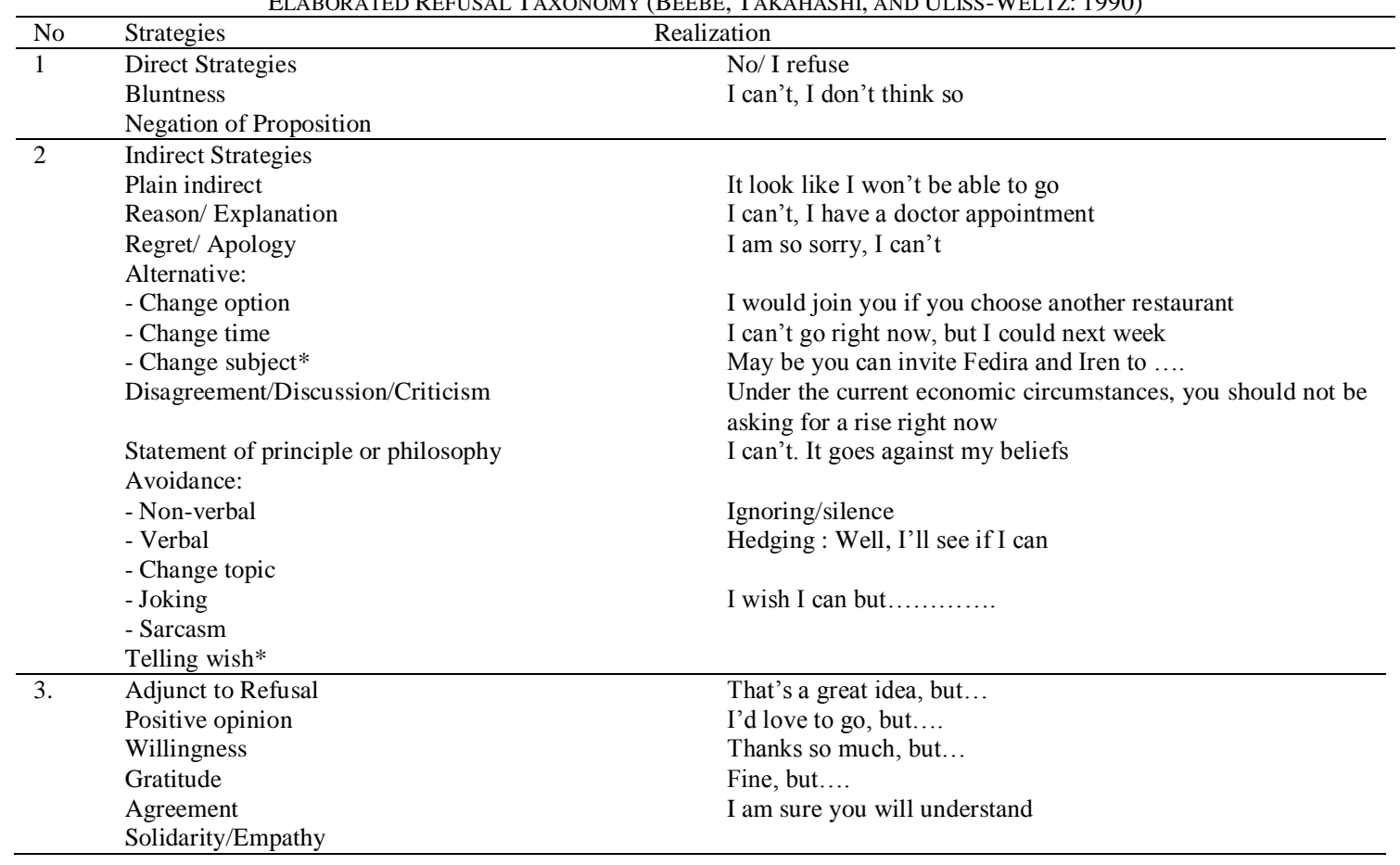

\section{B. Participants' Appropriateness and Accuracy of Refusals}

Speakers' pragmatic competence can be drawn on the basis of their performance and production of semantic formulas they successfully made to respond to the invitation in DCT.

1. Participants' Appropriateness 
Appropriateness is achieved when speakers could produce utterance in line with hearers' sociocultural status. It is one of pragmatic competences (sociopragmatic) which rules that speakers have to produce utterances pursuant to their interlocutors' social status. This competence requires that speakers should be sensitive to hearers' personal data.

Data of participants' performance of refusal semantic formula indicates that they could produce appropriate utterances. They were able to produce utterances which are in line with the hearer's social aspects. According to DCT, speakers have to make refusal to hearer who has similar social aspects, such as low or similar power $(-\mathrm{P})$, similar distance $(-\mathrm{D})$, and similar rank of imposition $(-\mathrm{R})$.

TABLE 6.

APPROPRIATENESS LEVEL

\begin{tabular}{llll}
\hline No & Strategies & APPROPRIATENESS LEVEL & Inappropriate \\
\hline 1 & Direct Strategies & $100 \%$ & $0 \%$ \\
2 & Indirect Strategies & $100 \%$ & $0 \%$ \\
3 & Adjunct to Refusal & $89,65 \%$ & $10,3 \%$ \\
\hline
\end{tabular}

Data analysis draws that the participants' refusal semantic formulas are generally appropriate. Their appropriateness level was considered to be excellent. Of the three kinds of strategies implemented, only one strategy (i.e. adjunct to refusal) contained low level of inappropriateness. It was noted only $9 \%$ inappropriateness occurred. As they had to respond to an invitation to hearer having $-\mathrm{P},-\mathrm{D}$, and $-\mathrm{R}$, they had actually to use non honorific expressions in order to avoid hearer' loosing face. However, they used, although in a single part of the whole expression, honorific expression using more polite choices of clause 'I would like to thanks for invitation', and 'I would be amazing and awesome...'. These expressions should be delivered to people they respect, who have higher power. In addition, the clauses are to be used to communicate with people who they are imposed as well as those who are not closed with the speakers $(+\mathrm{D})$. The expressions were delivered in DCT by students who, according to researcher's observation during English lessons and special in depth interview to both participants, had the same proficiency level of English as other students. This can be proven that they both were able to construct even long sentences then the others and used more than one strategies in the refusal strategy. The fact implied that participants with high proficiency level did not necessarily make appropriate (apart from accurate) sentences. In another word, it can be concluded that this finding was not in line with that of Cordina-Espurz (2013) that lower proficient learners perform less competency.

2. Participants' Accuracy

Participants' accuracy seemed to be lower than their appropriateness. Participants seemed to have obstacles in performing the three strategies, however the obstacles varied depending on strategies level of complexity. Of the three strategies of refusal, direct strategies were the most difficult and indirect strategies were the least. Speakers produced $65,5 \%$ inaccuracy and only 34,4\% accuracy. However, it cannot be generalized since limited number of formulas they could produce (4 semantic formulas). This number is considered not representative to indicate that direct strategies are the most difficult ones.

Indirect strategies were easier for the participants. They could produce $68,1 \%$ accurate sentences and $31,8 \%$ accurate sentences of refusal indirect strategies. Seeing from the fact that there were 29 expressions of indirect strategies, the result of analysis can be considered reliable. And, adjunct to refusal was the strategy which share same level of difficulty $(50 \%)$.

TABLE 7.

ACCURACY LEVEL

\begin{tabular}{lllll}
\hline No & Strategies & Number of Formulas & Accurate & Inaccurate \\
\hline 1 & Direct Strategies & 4 & $34,4 \%$ & $65,5 \%$ \\
2 & Indirect Strategies & 29 & $68,1 \%$ & $31,8 \%$ \\
3 & Adjunct to Refusal & 22 & $50 \%$ & $50 \%$ \\
\hline
\end{tabular}

Inaccuracy of sentences produced by participant indicated incompetence of participants' pragmalinguistically. There are a number of pragmalinguistic or grammar errors found in the data. Pragmalinguistic errors comprised form and function errors of sentences. The grammatical errors included spelling, subject - verb agreement, modal verb - verb agreement, two words-verb, verb omission, verb form, and prepositional phrase.

In terms of spelling, they exposed some words which are meaningful on the bases of semantics and acceptable on the basis of structure but emerged with wrong spelling, for instance 'can not', ' frien to refer to friend', 'may to refer to my'. Some problems on the use of modal verbs also occurred, such as 'I must to finish', I must to do', 'I should to do', I can not watching', 'I can't to accompany', 'I am can not to company you'. Some inaccuracy was triggered by the inconsistence in using 'prepositions', for instances, 'at Saturday' or 'in Saturday' to refer to 'on Saturday', 'in next Saturday' which refers to 'on next Saturday'. In addition, the use of preposition to be added with verb was also found incorrect, suc as 'May be you can invite Fedira and Iren for accompany you come to the concert', and 'I am so happy you invite me for join concert'. The use of verb 'want' was incorrect grammatically, such as 'I want to coming', 'actually, we wnt to watching'. The use of personal pronoun was also found incorrect, for instance 'Me and my friend have to do an English assignment'. 
It was obviously recognized that the errors were mostly made by participants having lower L2 competence. The case of inaccuracy which was found in participants' written expression in DCT implied that the lower proficient learners performed less competence of L2 (in this case, grammar competence). This finding is supportive to and consistent with that proposed by Cordina-Espurz (2013).

\section{CONCLUSION}

In conclusion, it can be underlined that there were three main strategies used by participants, they are direct strategy, indirect strategy, and adjunct to refusals. It is in line with refusal taxonomy proposed by Beebe, Takahashi, and UlissWeltz (1990), however, there were two point of new finding found to add the strategies in Beebe's et al. (1990) taxonomy, they are 'Alternative (change subject)', and 'telling wish', both of which were under indirect strategies. Of the three strategies, two strategies were used quite frequently, they were indirect strategy and adjunct to refusals, with percentage of use $52,7 \%$ and $40 \%$ respectively. However, direct strategy was used quite rarely (7,2\%). Participants' appropriateness and accuracy ware emerging a contradictive result. Their appropriateness of speech acts of refusal outweighed their accuracy. In terms of their appropriateness, their indirect strategies, direct strategies, and adjunct to refusals were $100 \%, 100 \%$, and $89,65 \%$ appropriate respectively. This data implied that they could comprehend and construct sentences for correct context (-P,-D,-R). This fact of participant utterances appropriateness leads in to a proposition that higher level of L2 proficiency does not guarantee participants' high appropriateness, which is in contrast with the finding of Cordina-Espurz (2013).

In term of accuracy, they were able to produce sentences with lower accuracy level for the three strategies. They are $34,4 \%, 68,1 \%$, and $50 \%$ accuracy for direct strategies, indirect strategies and adjunct to refusal respectively. This facts implied a proposition which is in line with Cordina-Espurz's (2013) idea that the lower the participants' proficiency, the lower accuracy level they are in.

The proposition needs to be further researched by undertaking studies on refusals or other speech acts considering that this study still has a number of limitation, such as instrument used to find data, number of participants involved, number of situation used to make DCT, and other aspect.

\section{REFERENCES}

[1] Abed, Ahmed Qadoury. (2011). "Pragmatic Transfer in Iraqi EFL Learners' Refusals". ISSN 1923-869X E-ISSN $1923-8703$. www.ccsenet.org/ IJEL International Journal of English Linguistics Vol. 1, No. 2; September 2011. Department of Translation, Faculty of Arts, The University of Al-Mustansiriyah, Baghdad, Iraq. Pp.166-185.

[2] Awert A. and Bromberek - Dyzman K. (2008). "Impossible requests: L2 users' sociopagmatics and pragmalinguistic choices in L1 acts of refusal". Eurosela Yearbook 8: 32-51.

[3] Beebe, L.M., Takahashi, T., \& Uliss-Weltz., R. (1990). Pragmatic Transfer in ESL refusals, In. R.C. Scarcella, E. Anderson and S.D. Krashen (Eds.) on Development communicative competence in a second language, Cambridge, M.A.: Newbury House Publishers. 55-77.

[4] Blum-Kulka, S., House, J., \& Kasper, G. (Eds.). (1989). Cross-cultural Pragmatics: Requests and apologies. Norwood, NJ: Ablex.

[5] Blum-Kulka, S. \& E. Olshtain. (1986). Too many words: Length of utterance and pragmatic failure. Studies in Second Language Acquisition 8, 165-180.

[6] Brown, Penelope dan Steven Levinson. (1987). Politeness: Some Universals in Language Usage. Cambridge: Cambridge university press.

[7] Cordina-Espurz, Victòria. (2013). "The role of proficiency in the production of refusals inEnglish in an instructed context". Utrecht Studies in Language and Communication 25 (2013): 121-146. (Universitat Jaume I).

[8] Ellis, R. (2008). The study of second language acquisition (2nd ed.). New York: Oxford University Press

[9] Felix-Brasdefer, J. C. (2004). "Iterlanguage Refusals: Linguistic Politeness and Length of Residence in the Target Community". Language Learning 54(4): 587-653

[10] Martínez-Flor, Alicia. (2013). "Learners' Production of Refusals: Interactive Written DCT Versus Oral Role-play". Utrecht Studies in Language and Communication 25 (2013): 175-211. (Universitat Jaume I).

[11] Olshtain, E. and A. Cohen (1983). "Apology: a Speech Act Set' in N. Wolfson and J. Elliott” (eds.). TESOL and Sociolinguistic Research. Rowley, MA: Newbury House.

[12] Ren, Wei. (2012). "Pragmatic Development in Chinese Speakers' L2 English Refusals". EUROSLA Yearbook 12 (2012), 63-87. doi 10.1075/eurosla.12.05ren issn 1568-1491/e-issn 1569-9749 c John Benjamins Publishing Company University of Bristol / University of Chinese Academy of Sciences.

[13] Tian, Xiufeng. (2014). "Investigating L2 Refusals: A Case Study of Chinese Native Speakers' L2 Pragmatic Competence". ISSN 1799-2591. Theory and Practice in Language Studies, Vol. 4, No. 1, pp. 212-216.

[14] Taguchi, Naoko. (2006). Analysis of Appropriateness in a Speech Act of Request In L2 English Pragmatics. International Pragmatics Association 16:4.513-533. January 2014 @ 2014 ACADEMY PUBLISHER Manufactured in Finland.

[15] Widanta, I. M. R. J. (2017). How should pragmatic be taught? International Journal of Language and Linguistics, Vol. 4, No. 2. www.ijlnet.com. June 2017, pp.110-115).

[16] Widanta, I. M. R. J. et al. (2018). Iterlanguage request modification: a case in vocational college. Journal of Physics: conference series. 953 012095. Iopscience.iop.org/issue/1742-6596/953/1/012095., 2018. 


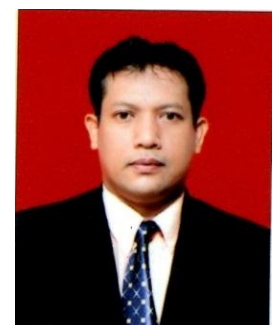

I Made Rai Jaya Widanta was born in Badung, Bali, Indonesia on 27th October 1973. He is a permanent lecturer of English at Mechanical Engineering Department, Bali State Polytechnic, Bali, Indonesia. He pursued bachelor degree (Sarjana Sastra or S.S.) in English literature at Warmadewa University in 1997. He completed his master program and pursued a degree of Magister Humaniora (M.Hum.) in linguistics in 2002 and doctorate program with Doktor (Dr.) degree in linguistics in 2017.

He has been teaching in both private and state universities as well as governmental and private companies. $\mathrm{He}$ has been teaching General English and English for Specific Purposes. In addition, he has also been administering English proficiency test, such as TOEFL, TOEIC, English Competence Test, and Proficiency Test of English. His research interests are developing learning model, first and second language acquisition, and interlanguage pragmatics.

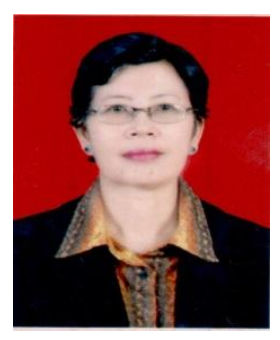

Ni Putu Somawati was born in Denpasar on 27 May 1963. She completed her bachelor program in English literature in Udayana University and was awarded Doctoranda (Dra.) degree in 1987. She continued her study to master program in management and was awarded Magiter Manajemen (M.M.) in Udayana University in 2005. He started her career as an English lecturer in Bali State Polytechnic in 1991. Her research interests includes development tourism, Englis literature, applied linguistics and English language teaching.

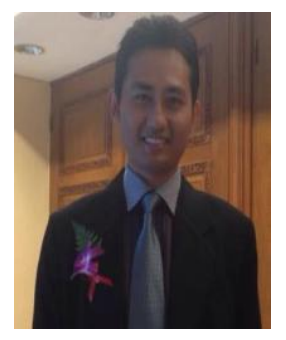

I Wayan Dana Ardika was born in Tabanan on 24 October 1984. He completed his bachelor program in English literature in Warmadewa University and was awarded Sarjana Sastra (S.S.) degree in 2006. He pursued his degree of Magiter Pendidikan (M.Pd.) in Ganesha University of Education in 2008. He started his career as an English lecturer in Bali State Polytechnic in 2009. His research interests are both in English education and English literature, including designing learning model, designing engineering dictionary, and pragmatics. 